\title{
The adverse health and social outcomes of sexual coercion: Experiences of young women in developing countries
}

\author{
Deepika Ganju \\ Population Council \\ William Finger \\ Shireen J. Jejeebhoy \\ Population Council \\ Vijaya Nidadavolu \\ K.G. Santhya \\ Population Council
}

See next page for additional authors

Follow this and additional works at: https://knowledgecommons.popcouncil.org/departments_sbsr-pgy

Part of the Family, Life Course, and Society Commons, Gender and Sexuality Commons, and the International Public Health Commons

How does access to this work benefit you? Let us know!

\section{Recommended Citation}

Ganju, Deepika, William Finger, Shireen J. Jejeebhoy, Vijaya Nidadavolu, K.G. Santhya, Iqbal Shah, Shyam Thapa, and Ina Warriner. 2004. "The adverse health and social outcomes of sexual coercion: Experiences of young women in developing countries," research brief. New Delhi: Population Council. 


\section{Authors}

Deepika Ganju, William Finger, Shireen J. Jejeebhoy, Vijaya Nidadavolu, K.G. Santhya, Iqbal Shah, Shyam Thapa, and Ina Warriner 


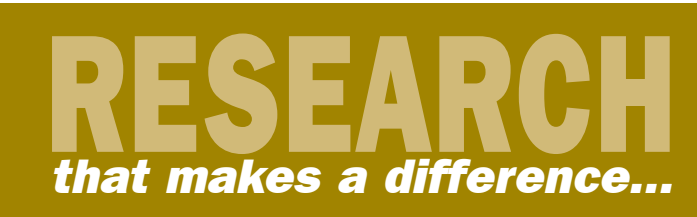

\section{THE ADVERSE HEALTH AND SOCIAL OUTCOMES OF SEXUAL COERCION: Experiences of young women in developing countries}

Although evidence from developing countries is limited, what is available suggests that significant numbers of young women have experienced coercive sex. Studies in diverse settings in Africa, Asia and Latin America reveal that forced sexual initiation and experiences are not uncommon in all of these settings. Moreover, a number of these women suffer repeated episodes of sexual violence and a considerable number also report incidents of childhood abuse. Many young victims of abuse fear disclosure as they feel they may be blamed for provoking the incident or stigmatized for having experienced it, and suffer such incidents in silence. ${ }^{1}$

Presentations at a meeting held in New Delhi in September 2003 (see box inside) highlighted findings from recent studies in diverse settings that suggest an association between early experiences of sexual violence and a range of adverse physical and mental health and social outcomes. Available evidence comes from diverse settings in Latin America, Africa and South Asia. ${ }^{2}$ However, given that data on the consequences of non-consensual sex are limited and restricted to a few geographical settings, the scale of the problem and its implications for policies and programmes are yet to be established.

The cross-sectional nature of available studies makes it difficult to establish definite causality between coercive sex and health and social outcomes; in order to establish such causality, studies are required that follow victims and non-victims of sexual coercion over time. Cross-sectional studies, while limited, can, however, establish associations between the experience of sexual coercion and adverse health and social outcomes.

\section{Associations between early coerced sex and compromised sexual and reproductive health}

Evidence shared at the New Delhi meeting revealed some striking similarities in experiences across settings. For example, compared to young women of similar age who did not experience sexual coercion, females who experienced coercion are more likely to experience subsequent incidents of forced sex, as well as (consensual) sexual risktaking behaviours including multiple sexual partners and non-use of condoms, and consequently increased risk of unintended pregnancy and sexually transmitted infections (STIs). They are also more likely to experience poor mental health outcomes, and alcohol and substance abuse. Notable associations highlighted at the meeting are discussed below.

\section{Vulnerability to subsequent non-consensual sex}

Women who have suffered abuse in childhood or during early adolescence continue to be vulnerable to sexual coercion. A study in Nicaragua reveals that women who had experienced severe abuse before the age of 13 years were more likely than other women to report severe sexual abuse subsequently. ${ }^{3}$ Similarly in Goa, India, school-going adolescents who had been abused were more likely than their peers to have experienced subsequent violence, with some reporting up to three such episodes in their lifetime. ${ }^{4}$ Women survivors of 


\section{The adverse health and social outcomes of sexual coercion: Experiences of young women in developing countries}

childhood incest in New Delhi, India also reported continued abuse that happened "often enough" or "every time he got a chance".

Young women who report forced first sex also appear to be more likely than those whose first sex was consensual to experience subsequent incidents of non-consensual sex. A World Health Organization multi-country study reveals that 60 per cent of women who had first sex by force subsequently experienced sexual violence with an intimate partner compared to 23-27 per cent of those whose first sex was consensual. ${ }^{6}$ Evidence from Thailand shows that young women who had forced first sex were more likely to experience sexual violence later in intimate partnerships. ${ }^{7}$ In Rakai, Uganda, too, women whose first sex was coercive continued to be vulnerable to sexual coercion within other subsequent partnerships. ${ }^{8}$

\section{Increased risk of subsequent unsafe consensual sex}

Early subsequent sexual activity

Systematic associations are evident between the experience of sexual coercion and subsequent sexual activity in studies in such diverse settings as India and the Caribbean. In Barbados, coercion in childhood or early adolescence increased the likelihood of sexual activity in adolescence. ${ }^{9}$ Victims of childhood incest in New Delhi, India, similarly, described how their abusive initiation into sex led them to being sexually active at a very early age. One woman said that the abuse had made her "become a woman overnight" and by early adolescence she had begun to "lead a very promiscuous existence and had no qualms about entering into sexual relationships with men" she found attractive. ${ }^{10}$ In Nicaragua, likewise, women who had experienced sexual abuse initiated their consensual sexual life earlier than those who had not experienced coerced sex. ${ }^{11}$

\section{Multiple consensual sexual partners}

Coercion in adolescence is associated with the greater likelihood of having multiple consensual sexual partners later in life. In Leon, Nicaragua, women who had been severely abused or had experienced attempted or completed rape were more likely to have had more sexual partners subsequently than women who had not been abused or had been moderately abused. ${ }^{12}$ Similarly, sexually abused women in Rakai, Uganda and women from the Central African Republic whose first sex was forced were more likely than women whose first sex was consensual to report two or more lifetime sexual partners. ${ }^{13}$

For many victims of childhood incest in New Delhi, India, early sexual abuse was perceived to have resulted in subsequent sexual risk-taking, and brief and unsatisfactory sexual relationships in adolescence and early adulthood. One women said that all her subsequent relationships with men were "sexualized" and as she had "been sleeping with so many men since an early age, it did not really matter if there was one more." Sex was perceived by women as an "ultimate winning weapon," and having multiple partners was linked with a sense of value, self-worth and a means of regaining lost power. ${ }^{14}$

\section{Non-use of condoms}

While evidence is sparse, there is a suggestion that early coercive sex may inhibit women's ability to negotiate condom use. In Rakai, Uganda, for example, sexually abused women were significantly less likely to report current contraceptive use, even with the most recent partner, compared to women who had not experienced sexual coercion. They were also significantly less likely to have used a condom during the last sexual encounter or within the past 6 months, or to have used a condom consistently. ${ }^{15}$ Victims of abuse were less likely to have discussed condom use with their partner compared to women who had not been abused. ${ }^{16}$

\section{Associations with unintended pregnancy} and infection

Compounding the trauma of forced sex are the inevitable direct consequences of unintended pregnancy, abortion and infection; there is also the suggestion that women who have suffered forced sex may have limited skills in negotiating safe sex or may practise sexual risk-taking behaviours, for instance, engaging in unprotected sex with multiple partners. ${ }^{17}$ In relationships with "sugar daddies" they can neither negotiate safe sex nor exercise choice in what to do if they become pregnant; when pregnancy occurs, they report forced abortions by their partners. ${ }^{18}$ 
Evidence from Latin America, South Asia and Africa suggests a link between forced sex and experiences of reproductive tract infection (RTI)/STI symptoms. Victims of childhood incest in New Delhi, India and sexually abused adolescents in Mexico revealed a history of STIs. ${ }^{19}$ In Rakai, Uganda women who experienced coercive first sex or coercive sex during their lifetime were consistently more likely to report symptoms suggestive of possible STIs/RTIs than women who had not had forced sex. ${ }^{20}$ Young women in Peru and Ethiopia who had experienced coercion were likewise more likely to report symptoms of STIs or vaginal discharge than women who had not been abused. ${ }^{21}$

The risk of acquiring HIV also appears to be high among sexually abused women. In Tanzania and Rwanda, HIV-positive women were significantly more likely than HIV-negative women to report prior physical abuse or coercive sex. ${ }^{22}$ Women in Uganda who had coerced sex had an eight times higher risk of acquiring HIV compared to women who had not been abused. ${ }^{23}$ In Rakai, Uganda, coercive first sex was associated with a 71 per cent higher risk of subsequent HIV acquisition. ${ }^{24}$

\section{Links between early coerced sex and poor mental health and psycho-social}

\section{outcomes}

Early experiences of coercion are associated with adverse psycho-social outcomes such as depression, low self-esteem and isolation. Sexually abused school-going adolescents in Goa, India for example, reported higher rates of non-specific physical complaints such as sexual discharge, as well as poor mental health, suicidal ideation, alcohol abuse and cigarette smoking than those who had not had coercive experiences. Low self-esteem could in some cases be linked to the lack of a supportive environment at home or in school. ${ }^{25}$ In Pakistan and Ethiopia, similarly, girls who had experienced coercion had feelings of guilt, sadness, rejection and hopelessness, and some reported attempting to commit suicide. ${ }^{26}$

For many victims of childhood incest in New Delhi, India, the effects of coercion were evident long after the incidents had ceased. Some reported that coercion had resulted in an inability to exercise sexual choice and "control or right over their own body." As one woman said: "I was trained as a child to understand my sexuality in ways that made no place for my own wishes and desires. I learnt therefore to accommodate the demands of men". Some experienced difficulty in forming trusting relationships subsequently: "The one thing that abuse does to people is to destroy their ability to relate to other people with love and trust". Women also reported mutilating themselves or contemplating suicide in order to cope with the pain or memories of the abuse, and in some cases sexual dysfunction: "I don't think I was able to enjoy sex....I was always very scared that I would be violated." Addiction to alcohol had resulted in an inability to make safe and positive choices in later sexual partnerships. ${ }^{27}$

Studies in Goa, India, and Ethiopia report that the experience of sexual abuse was associated with adverse social outcomes such as discontinuing school and poor academic performance. ${ }^{28}$ Evidence from South Africa suggests that where forced sex results in premarital pregnancy, the traumatic experiences of abuse and unintended pregnancy are compounded by yet another adverse consequence: that of withdrawal from school. ${ }^{29}$

At the New Delhi meeting a panel of Indian youth shared the perspectives of young people on forced sex and its associations with reproductive health and mental and emotional well-being. Their presentations reiterated the findings that coerced sex can happen repeatedly, and is linked with adverse mental and emotional outcomes such as depression, isolation, loss of self-esteem and attempted suicide. The young panellists highlighted the stigma and discrimination that young girls face, whether as a consequence of date rape, or coercion perpetrated by a family member or a neighbourhood acquaintance.

\section{Summing up}

Many adolescents and young females in developing countries have experienced coerced sex, either at initiation or subsequently. Coercive sexual experiences are observed to be associated with serious and far-reaching outcomes in the lives of young females. For one, sexual coercion is not a one-

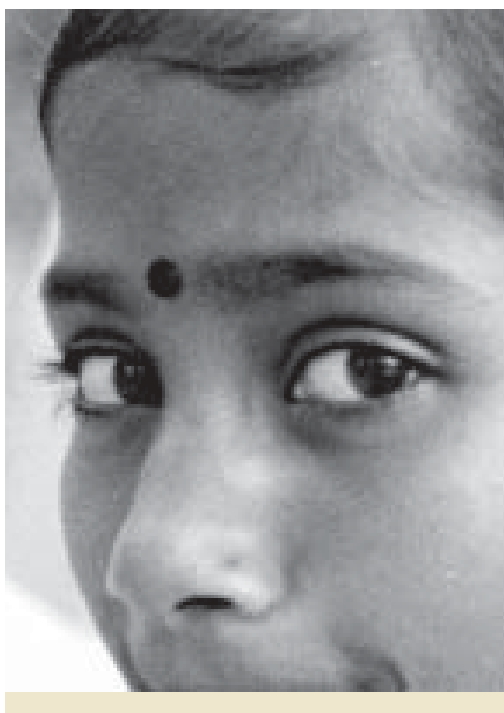

Global consultative meeting on nonconsensual sex among young people

In September 2003, a global consultative meeting on nonconsensual sex among young people in developing countries was held in New Delhi, India. The meeting was organized by Population Council in collaboration with World Health Organization/Department of Reproductive Health and Research, and Family Health International/YouthNet. Participants included researchers, legal analysts, representatives from community-based NGOs, policy makers, and young people themselves.

Sessions examined the following issues in relation to non-consensual sex: experiences of young females and males: prevalence, forms and contexts; youth perspectives, through a panel of seven youth; patterns of transactional sex; roles of the legal system; outcomes of coercion at the individual and community level; interventions to prevent non-consensual sex, and to support and treat victims; and research design and methods. 
time event and those who experience it are also more likely than others to experience both subsequent non-consensual sex and risky consensual sexual behaviours both in adolescence and early adulthood. Unintended pregnancy and abortion as well as the experience of STIs, including HIV, appear to be more likely among young females who have experienced coercive sex than among others. Finally, adverse mental health and psycho-social outcomes are reported, including low self-esteem and depression, as well as substance abuse.

\section{Recommendations for action}

Presentations at the New Delhi meeting highlighted the need for urgent programmatic action to address young people's vulnerability to coercive sex and possible far-reaching consequences. These include:

- Young people should be informed about and aware of their rights and their ability to exercise choice in reproductive and sexual health matters.
- Life and livelihood skills must sharpen negotiation skills among young females, both in general and with specific reference to possible non-consensual sexual advances.

- Young people must be informed about where to go for redress in case they experience coercion.

- Specific efforts are needed to provide a supportive and non-judgemental environment for victims of coercion, including parents, teachers and health care providers.

- Health care, police and legal systems must be sensitized to and incorporate measures to address the needs of young victims and mitigate the adverse health and social outcomes associated with victims.

- Recognition of subsequent risk-taking and adverse consequences reiterate the need for sensitive counselling of victims.

- There is a need to develop a solid evidence base that establishes causality between the experience of forced sex and reproductive health and psycho-social consequences at the individual and the larger systemic and societal levels.
(P) Population Council

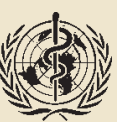

World Health Organization

\section{YouthNet}

For further information please contact: Population Council Zone 5A, India Habitat Centre Lodi Road, New Delhi - 110003 Ph.: +91 11 24642901/2 Fax: +911124642903 email: info@pcindia.org

www.popcouncil.org

Deepika Ganju, in collaboration with Shireen Jejeebhoy, Vijaya Nidadavolu and K.G. Santhya (Population Council); William Finger and Shyam Thapa (Family Health International/ YouthNet); and lqbal Shah and Ina Warriner (World Health Organization/ Reproductive Health and Research).

\section{References}

References to presentations from Non-consensual Sexual Experiences of Young People in Developing Countries: A Consultative Meeting, New Delhi, India, September 22-25, 2003 are noted as New Delhi meeting.

1 Jejeebhoy, S.J. and S. Bott. 2003. Non-consensual sexual experiences of young people: A review of the evidence from developing countries. Population Council Working Paper No. 16, New Delhi.

2 Ellsberg, M., Coerced sex among adolescents in Latin America and the Caribbean, New Delhi meeting; Gupta, A., Incest in Indian families: Learnings from a support center for adult women survivors, New Delhi meeting; Jejeebhoy and Bott, 2003; Koenig, M. et al., The sequelae of adolescent coercive sex: Evidence from Rakai, Uganda, New Delhi meeting; Patel, V., The prevalence and correlates of sexual abuse among school-based adolescents in Goa, New Delhi meeting.

3 Ellsberg, New Delhi meeting.

4 Patel, V. and G. Andrew. 2001. Gender, sexual abuse and risk behaviours in adolescents: A crosssectional survey in schools in Goa. National Medical Journal of India 14(5): 263-267.

5 Gupta, New Delhi meeting.

6 Im-em, W. et al. 2003. Sexual coercion among women in Thailand: Results from the WHO multicountry study on women's health and life experiences, New Delhi meeting.

7 Im-em, New Delhi meeting.

8 Koenig et al., New Delhi meeting.

9 Handwerker, W.P. 1993. Gender power differences between parents and high-risk sexual behaviour by their children: AIDS/STD risk factors extend to a prior generation. Journal of Women's Health 2-3: 301-316.

10 Gupta, New Delhi meeting.

11 Ellsberg, New Delhi meeting.

12 Ellsberg, New Delhi meeting.

13 Koenig et al., New Delhi meeting; Somse, P., M.K Chapko and R.V. Hawkins. 1993. Multiple sexual partners: Results of a national HIV/AIDS survey in the Central African Republic. AIDS 7(4): 579-583.

14 Gupta, New Delhi meeting.

15 Koenig et al., New Delhi meeting.

16 Koenig et al., New Delhi meeting.

17 Billings, D.L. 2003. Sexual coercion, unintended pregnancy and abortion: Exploring the linkages in Mexico, New Delhi meeting; Caceres, C.F. et al. 1997. Young people and the structure of sexual risks in Lima. AIDS 11(supplement 1): 567-577; Ellsberg, New Delhi meeting; Hof, C. and A. Richters. 1999. Exploring intersections between teenage pregnancy and gender violence: Lessons from Zimbabwe. African Journal of Reproductive Health 3(1): 51-65; Koenig et al., New Delhi meeting; Mulugeta, E., M. Kassaye and Y. Berhane. 1998. Prevalence and outcomes of sexual violence among high school students. Ethiopian Medical Journal 36: 167-174; Worku, A. and M. Addisie. 2002. Sexual violence among female high school students in Debark, North west Ethiopia. East African Medical Journal 79(2): 96-99. 18 Kuate-Defo, B. 2003. What we know about young people's relationships with sugar daddies and mummies, New Delhi meeting.

19 Billings, New Delhi meeting; Gupta, New Delhi meeting.

20 Koenig et al., New Delhi meeting.

21 Caceres et al., op. cit.; Mulugeta et al., op. cit.; Worku and Addisie, op. cit.

22 Maman, S. et al. 2002. HIV positive women report more lifetime partner violence: Directions for future research and interventions. Social Science and Medicine 50: 459-478; van der Straten, A. et al. 1995. Couple communication, sexual coercion and HIV risk reduction in Kigali, Rwanda. AIDS 9:935-944.

23 Quigley, M. et al. 2000. Case control study of risk factors for incident HIV infection in rural Uganda. Journal of AIDS 5: 418-425.

24 Koenig et al., New Delhi meeting.

25 Patel, New Delhi meeting.

26 Mulugeta et al., op. cit.; UNESCAP et al. 2001. Sexually Abused and Sexually Exploited Children and Youth in Pakistan: A Qualitative Assessment of their Health Needs and Available Services in Selected Provinces. Bangkok: UNESCAP; Worku and Addisie, op. cit.

27 Gupta, New Delhi meeting.

28 Mulugeta et al., op. cit.; Patel, New Delhi meeting.

29 Wood, K. and R. Jewkes. 2001. 'Dangerous' love: Reflections on violence among Xhosa township youth. In Changing Men in Southern Africa, ed. R. Morrell. Pietermaritzburg: University of Natal Press, pp. 317-336. 